\title{
Commentary Commemoration
}

\section{In Memory of Professor Hans Dieter Klenk}

\author{
MOE \& NHC Key Laboratory of Medical Molecular Virology Team ${ }^{1}$
}

Dr. Hans Dieter Klenk, an international renowned virologist, former President of the German Society of Virology, and a great friend and collaborator of scientists in China, passed away on June 02, 2021.

Hans Dieter Klenk studied medicine and biochemistry in Tübingen, Vienna, and Cologne. From 1967 to 1970 , he was a visiting scientist in the laboratory of Purnell Choppin at Rockefeller University in New York. In 1973 and in 1985 he was a professor of virology at the Philipps University in Marburg and became Director of the Institute of Virology until his retirement in 2007.

Prof. Klenk's successful research concentrated on the role of the surface proteins hemagglutinin and neuraminidase in the pathogenesis of influenza. He was also interested in other emerging viruses that threaten public health and has established the central research direction of the Marburg Institute of Virology, which is still actively pursued today.

Prof. Klenk received numerous highly respected scientific awards, such as the Robert Koch Medal, the Ernst Jung Medal for Medicine, and the Emil von Behring Prize. He was awarded the Federal Cross of Merit 1st Class and the VCanBio International Collaboration Award.

Hans Dieter Klenk had a decisive influence on the Marburg Institute of Virology and established its international orientation and visibility. Under his leadership, numerous young scientists had the opportunity to develop their own scientific profile and to be appointed to leading positions nationally and

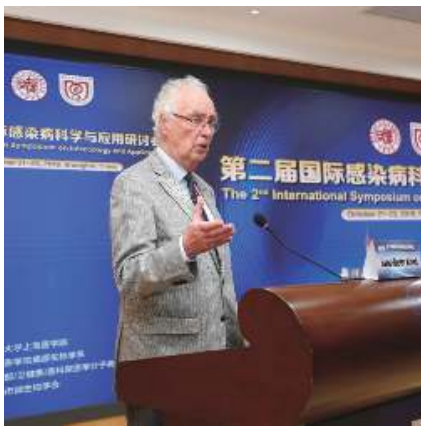

Prof. Hans Dieter Klenk gave a talk at a symposium in Shanghai, China (2018)

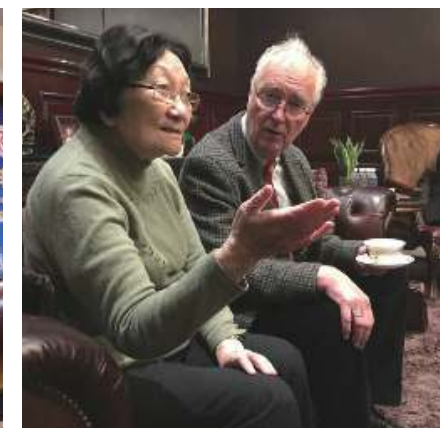

Prof. Hans Dieter Klenk with Prof. Yumei Wen in Tianjin, China internationally.

He coordinated numerous scientific consortia including the Collaborative Research Center 286 of the German Research Foundation and was active as chairman for the scientific advisory boards of several research institutions including Georg-Speyer-Haus, Feldberg Foundation for Anglo-German Scientific Exchange, Shanghai-Pasteur Institute, and the Key Laboratory Institute on Medical Molecular Virology of China.

During the outbreak of SARS, he led a group of Germen scientists to initiate Sino-German collaboration in studies on emerging infectious diseases. Furthermore, he served with Professor Yumei Wen as the founding co-editors-in-chief of the journal Emerging Microbes \& Infections, which is now a wellrecognized international scientific journal published by Taylor \& Francis online.

Prof. Klenk leaves behind a huge legacy on a professional and personal level. His many publications, honors, and recognitions bear witness to his astuteness, precision, and nature of always questioning and seeking answers. His devotion to help others and his ardent pursuit for scientific problems has been a respectful model for all of us, and his memory will live on.

doi: $10.46234 / \mathrm{ccdcw} 2021.171$

\footnotetext{
${ }^{1}$ MOE \& NHC Key Laboratory of Medical Molecular Virology, Shanghai Medical College, Fudan University, Shanghai, China.
}

Submitted: August 03, 2021; Accepted: August 05, 2021

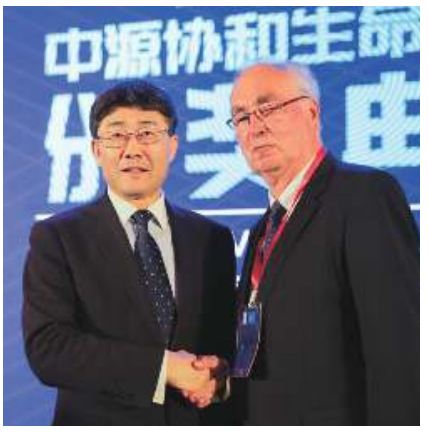

Prof. Hans Dieter Klenk with Prof. George F. Gao at VCanBio Award Ceremony (2018)

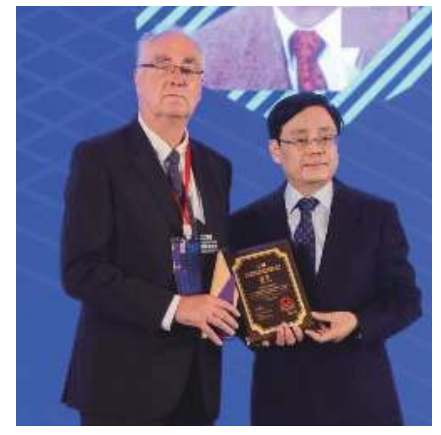

Prof. Wei He awarding Prof. Hans Dieter Klenk the VCanBio Award (2018) 